\title{
Feminilidades a dedo. Danças, performances e erotismos no show business brasileiro
}

\author{
Raphael Bispo dos Santos \\ IUPERJ/ UCAM
}

Resumo: Durante os anos 1970 e 1980, um conjunto de dançarinas sensuais, as chacretes, ganhou destaque na televisão brasileira. Este artigo procura analisar a necessária fabricação por parte dessas dançarinas de uma "performance de gênero" hiperfeminina para a obtenção do sucesso como chacrete, o que chamaremos neste trabalho de "performance de superfêmea". Sendo a estética e a corporalidade essenciais para a atividade de uma girl, o artigo irá focar precisamente na dança cênica e midiatizada dessas mulheres executadas para a TV.

Palavras-Chave: dança; gênero; sexualidade; televisão. 


\begin{abstract}
During the 1970 s and 1980s, a group of sexy dancers, the chacretes, rose to prominence in Brazilian television. This article seeks to analyze the necessary manufacturing by this dancers of a "gender performance" extremely female to achieve success as chacrete, what we will call in this work as "superfêmea performance". Being the aesthetics and the body essential for the activity of a girl, the article will focus specifically on the scenic and mediated dance that these women performed at the TV.
\end{abstract}

Keywords: dance; gender; sexuality; television.

Resumen: Durante los años 1970 y 1980, un grupo de bailarines sexy, las chacretes, saltó a la fama en la televisión brasileña. Este artículo pretende analizar la necesaria fabricación por estos bailarines de una "performance de género" extremadamente femenina para alcanzar el éxito como chacrete, lo que vamos a llamar a esta obra de "performance de superfêmea". Siendo la estética y el cuerpo esencial para la actividad de una girl, el artículo se centrará específicamente en la escénica danza realizada por estas mujeres en la TV.

Palabra Clave: danza; género; sexualidad; televisión. 


\section{Introdução}

Durante os anos 1970 e 1980, um conjunto de dançarinas sensuais, as chacretes, ganhou destaque na televisão. Além de auxiliar o apresentador Abelardo Barbosa, o Chacrinha ${ }^{1}$, em programas de auditório, compunha paralelamente um crescente mercado erótico, estendendo suas atuações para as boates-revistas, a pornochanchada, os ensaios sensuais e a prática de programas de luxo. Nesse sentido, devido a tal ênfase erótica no desempenho das atividades de uma girl da TV, a estética e a corporalidade sempre foram questões essenciais para o sucesso profissional. Em outro lugar (BISPO, 2012), pudemos analisar em detalhes o quanto a beleza, o interesse pela dança, o corpo e suas formas eram marcas que distinguiam as chacretes e caracterizavam essa ocupação profissional. A vocação parecia estar inscrita no físico, na aparência. $O$ corpo era constantemente tematizado como imprescindível na definição do que era a atividade e nas possibilidades de ingresso na carreira.

No entanto, outros atributos tornavam-se também essenciais para o sucesso das jovens, para além dos contornos físico-corporais propriamente ditos. Os diretores do programa de Chacrinha costumavam se referir a eles por expressões como savoir a faire e sex appeal. Tratava-se de um modo específico das chacretes se portarem durante suas exibições na televisão, principalmente nas danças que executavam. Logo, elas não só deviam ter um tipo físico específico, mas também evocar a todo instante uma imagem de mulher superexcitada e sempre disponível ao sexo casual, servindo-se de seus "corpos fartos" para isso. Desde o processo de seleção, esses produtores já atentavam para gestos, trejeitos e estilos que evocassem tal imaginário erótico.

Sendo assim, este artigo procura justamente analisar essa necessária fabricação de uma performance de gênero hiperfeminina por parte dessas dançarinas do mundo artístico comercial televisivo dos anos 1970/80. Mais precisamente, proponho aqui investigar a dança cênica e midiatizada das chacretes, executada durante os programas de Chacrinha para uma ampla e diversificada plateia de telespectadores. A ideia é demonstrar que a proposta performática de suas danças era construir tais girls como mais mulheres do que qualquer outra mulher, parafraseando Perlongher (2008: 100), visto que exageravam e dramatizavam a feminilidade mais convencional em suas

\footnotetext{
${ }^{1}$ Abelardo Barbosa, o Chacrinha, é considerado um dos maiores apresentadores e comunicadores da televisão brasileira. Sua trajetória teve início no rádio mas o sucesso maior foi mesmo quando começou a comandar programas de auditório como a "Buzina do Chacrinha" e a "Discoteca do Chacrinha" em diferentes emissoras do país. Chacrinha morreu no ano de 1986, mas até hoje é lembrado pela sua originalidade e capacidade de "comandar as massas", como lembra a canção de Gilberto Gil, “Aquele Abraço”.
} 
apresentações - borrando ou mesmo reificando certas fronteiras de gênero e da sexualidade mais hegemônicas -, atitude essa que chamaremos neste trabalho de performance de superfêmea.

Isso porque, seguindo Butler (2003: 194), pode-se dizer que tais performances exageradas das chacretes denunciavam o quanto o feminino/ser mulher não é algo tão estável e ontológico assim, mas fabricações sustentadas por signos corpóreos e outros meios discursivos. Nos programas de auditório, as fabricações do feminino se davam particularmente na forma como as mulheres interagiam no palco. Suas habilidades performáticas de superfêmea, em última instância, eram provas de sua efetiva capacidade para ser chacrete e obter sucesso com a atividade.

Gostaria de, a partir de agora, detalhar essa questão da "repetição estilizada de atos" (Butler, 2003: 200) que produzia um efeito de gênero hiperfeminino entre as dançarinas, tendo como base as dinâmicas de palco dos programas de Chacrinha ${ }^{2}$.

\section{Circuito integrado}

As chacretes possuíam uma força de comunicação tão intensa quanto era a sua imagem no conjunto do espetáculo televisivo comandado pelo Velho Guerreiro em programas como a "Discoteca do Chacrinha" e o "Cassino do Chacrinha”. A dança era sua melhor forma de interação com a plateia, seja o auditório propriamente dito, seja quem lhes assistia pela TV. No entanto, é preciso atentar para as peculiaridades dessa dança. Isso porque ela era elaborada numa articulação com a tecnologia televisiva. Dançava-se para as câmeras, num cenário montado em um estúdio de gravação, tudo disposto e organizado com a finalidade última de se transmitirem imagens por meio de antenas e sinais de longa distância. Quando Haraway (2009: 76) formula a expressão "mulheres no circuito integrado", ela procura justamente aludir às configurações das dinâmicas sociais que passam cada vez mais a serem mediadas pelas novas tecnologias. As mulheres e suas práticas cotidianas são reestruturadas por meio das "relações sociais da ciência e tecnologia", articulação esta que acaba por compor significados específicos a seus corpos. Seguindo Haraway, a dança das chacretes precisa ser compreendida em sua integração a um circuito sócio-técnico emaranhado de linguagens audiovisuais e técnicas de gravação próprias, cuja centralidade das dinâmicas de

2 Fiz uso de inúmeros vídeos disponíveis no site youtube e reunidos por fãs em outras páginas virtuais para acompanhar as dinâmicas dos shows de Chacrinha. A Rede Globo, por meio de seu projeto de apoio a pesquisas, também me cedeu dois programas da década de 1980 para análise. Agradeço a disposição e o empenho da equipe do Globo Universidade para com meus interesses de pesquisa. Cabe destacar que não pude entrar em contato com imagens em movimento da década de 1970, simplesmente pelo fato de elas não mais existirem, seja porque tais apresentações eram ao vivo, seja por não haver na época uma preocupação de guardá-las como um "lugar de memória". Assim, nunca poderemos ver como a trupe da primeira geração de chacretes performatizava a superfêmea. Certamente, há diferenças com o que é aqui exposto. No entanto, a fim de estimular essa reflexão, optei por dedicar-me à análise de vídeos em que a maioria das chacretes em cena compõe a segunda geração, a dos anos 1980. 
funcionamento do maquinário de filmografia repercutia diretamente na forma como se apresentavam, se comunicavam e davam significados aos seus corpos. As chacretes se faziam nas tecnologias de transmissão televisivas.

Uma anedota recorrente entre as chacretes elucida bem a importância de suas integrações com a tecnologia. A boca miúda diz que o maior "comedor" de girls não era um artista famoso, mas um cameraman. O funcionário trocava sexo por uma maior quantidade de closes ao longo das gravações. Chacrinha ficava atento a essas negociações, já que valorizava uma exibição harmoniosa de todas elas no vídeo. Quando uma chacrete "deu 75 vezes no ar", ou seja, foi filmada em primeiro plano durante 75 vezes ao longo de um único programa, o apresentador decidiu por demitir a equipe técnica que permitiu tal privilégio. Disse ele sobre o caso:

\begin{abstract}
Eu gravo os meus programas e vejo depois e eu vi, ela [uma certa chacrete] deu, assim, apareceu 75 vezes (risos). Quer dizer, estava de transa com o produtor, que só a focalizava. Mandei os dois embora. (...) Elas [as chacretes] já sabem, se fizerem vão para rua e o cara também. Não somente para manter a disciplina, mas para me dar um certo descanso também. Às vezes acontece isso de uma aparecer mais e a outra menos. É por isso que o Leleco [produtor e filho de Chacrinha] fica no estúdio, ao lado do diretor de TV; mesmo que o diretor queira fazer, ele não faz porque o Leleco está lá, tá entendendo? Se ele força a imagem em uma delas, isso seria um problema, porque todas têm que aparecer igual. É como um jogador de futebol, se o locutor cisma com um jogador, só fala dele, o torcedor fica com raiva (Revista Homem, 1980, n. 27-B, p. 7, edição especial).
\end{abstract}

A dança das chacretes fundamentava-se nos diversos pontos-de-vista que se impunham através do maquinário. Até a imagem final recebida pelo telespectador, tinham-se as ações do diretor, que controlava e selecionava trechos num monitor; as do produtor, que podia efetuar cortes arbitrários; as do cameraman, que selecionava ângulos da filmagem etc. Em termos de edição audiovisual, as dançarinas no "circuito integrado" da TV eram consideradas uma "vírgula" já que serviam como um recurso a ser filmado com o intuito de "descansar" rapidamente uma imagem extensa em foco3. O emprego do termo "vírgula" pela equipe sintetiza bem o papel um tanto secundário das dançarinas, embora imprescindível para o ritmo da atração. Portanto, as chacretes serviam como rápidas conexões entre outras imagens mais prolongadas. Era a oportunidade que tinham para cumprir sua missão. Um diretor dizia serem elas "o elemento plástico mais bonito que existe em cena", compondo o ritmo feérico que marcava o programa4. As chacretes ofereciam movimento e garantiam o clima de festa. A descrição do mesmo diretor elucida bem esse formato de edição agitado e a função "vírgula" das dançarinas:

\footnotetext{
Com as pernas de Lucinha Apache, uma tomada rápida do auditório, um close do calouro, um corte na expressão facial do Chacrinha, um plano geral do auditório, o sorriso da Débora, novamente o calouro, o júri, a Índia Poti, o Chacrinha apertando a buzina, um plano geral das chacretes dançando: eis a minha fórmula para tornar o show movimentado. Uso esses sem precisar fazer mágicas.
}

\footnotetext{
3A menção a idéia das chacretes como "vírgulas" está numa reportagem publicada no periódico em Diário de Notícias, 9 de novembro de 1973, p. 15 (acervo pessoal de Índia Potira).

4 Idem.
} 


\section{Aprendendo técnicas corporais}

A comunicabilidade das chacretes era permitida pelos planos fechados e pelos travellings dos câmeras. Através desses recursos audiovisuais, se faziam mais femininas por um intenso uso de gestos corporais e pela adoção de uma postura específica. Logo, através dessas atitudes particulares diante do maquinário, é possível descrever a estilização dos atos femininos que suas performances de superfêmea ensejavam, colocando em xeque a "realidade de gênero" (Butler, 2003: 201). Elas encaravam maliciosamente o telespectador, modificando seus olhares, algumas piscando, outras prendendo os lábios sem deixar de sorrir, realizando também movimentos leves e sensuais com os braços e pernas, aludindo ao intercurso sexual. Seguindo o argumento clássicos de Mauss (2003), a performance hiperfeminina de uma chacrete requer uma habilidade na manipulação de determinadas "técnicas corporais", sendo a aprendizagem de como controlar tais técnicas um requisito básico para o bom desempenho na ocupação. Uma superfêmea deve saber servir-se oportunamente de seu corpo, dominando práticas em sua maioria não verbais e de alto teor erótico. Logo, toda a sensualidade das chacretes não era "natural", no sentido de ser compreendida como inata a seus corpos, mas algo impregnado de cargas simbólicas e apreendido ao longo de suas trajetórias de dançarinas. " $\mathrm{E}$ preciso ver técnicas e a obra da razão prática coletiva e individual, lá onde geralmente se vê apenas a alma e suas faculdades de repetição" (Mauss, 2003: 404).

Por exemplo: algo muito comum entre as chacretes nos dias de hoje é destacar figuras do mundo artístico como fonte de inspiração e aprendizagem. A sensualidade é sempre vista por elas como algo que adquiriram com o passar dos anos, nunca inata. Apenas seus "corpos fartos" são tidos como naturais, divinos (mais detalhes em $X, 2012$ ). É possível dominar a sensualidade quando se têm tutores e/ou pessoas que servem de modelo. Inclusive, adquiridos tais conhecimentos, elas poderiam passá-los adiante. Nas lembranças das chacretes, são constantes as afirmações de que nos momentos iniciais da carreira, a timidez, o embaraço e a falta de traquejo imperavam em suas apresentações. Apenas a partir de certo contato com figuras bastante sensuais foi que conseguiram o sex appeal tão valorizado, romperam o ostracismo e puderam até mesmo ensiná-lo posteriormente a novatas.

A chacrete Índia Potira, por exemplo, costuma depositar a aprendizagem da sensualidade em dois grupos específicos. Com as vedetes, diz ter aprendido a caminhar e rebolar de maneira insinuante. Nunca esqueceu os ensinamentos 
quando criança de Mara Rúbia, uma dos grandes nomes do teatro de revista: uma verdadeira mulher deve ser sensual até mesmo descendo escadas. Índia costumava subir e descer algumas escadarias dezenas de vezes durante o dia, a fim de ensaiar e aprender a ser sensual tal como a sugestão de Mara. O andar na escada, segundo ela, permite perceber de longe a capacidade de sedução feminina. Mulheres mal-ajambradas descem de forma torta e arcada uma escadaria, olhando para o chão e pouco atentas aos passos executados. Já as sensuais irradiam erotismo numa descida altiva e milimetricamente calculada, se possível num salto-alto capaz de valorizar as pernas e nádegas.

Índia também costuma dizer que sempre se inspirou nas travestis para incrementar seu visual. Os grandes cílios, a maquiagem pesada, as roupas coloridas e chamativas, todos os excessos de figurino ela credita à cena dos "transformistas", que chegavam a frequentar os programas de Chacrinha quando a censura permitia5. As travestis são apontadas como modelos de sensualidade e fonte de inspiração entre as chacretes. No sentido proposto por Butler (2002), o gênero é performatizado nas práticas diárias, estando para além dos corpos e suas anatomias. Assim, a hiperfeminilidade é tão treinada e apreendida pelas chacretes que literalmente muitas aprenderam a ser "mulher" em seus gestos e trejeitos justamente com quem não nasceu num corpo com vagina. Sem a famosa "transformista" Rogéria - que nos anos 1970 brilhava em boates brasileiras e estrangeiras - Rita Cadillac diz que nada seria em termos artísticos. Rompeu toda a sua timidez com os incentivos dela. Aprendeu a se maquiar, a usar as mãos, a emitir olhares, enfim, com Rogéria adquiriu boa parte das técnicas necessárias para ser "bem mulher".

\begin{abstract}
Rogéria apareceu num dos shows [de Haroldo Costa] quando nós íamos viajar. Nós íamos para Porto Rico. E aquela mulher apareceu na minha vida! Ela chegou e falou: 'você é uma menina bonita, gostosa, poderosa. Mas não sabe usar isso. Primeira coisa, esse cabelo'. Pintei o cabelo! Ela me ensinou basicamente a maquiagem. (...) Ela me ensinou a ser gostosa, a usar o olhar, a sensualidade, saber usar o corpo. Ela me incentivou a ser uma cópia feminina dela ${ }^{6}$.
\end{abstract}

\title{
Gestos e posturas
}

A gramática do olhar aprendida por Rita a partir de Rogéria, por exemplo, era central nas apresentações das chacretes. Suas histórias sobre esse tema partem de uma proposta de estabelecer um "olho no olho" com o público

5 Existe uma cena artística travesti ("transformista") conectada às chacretes e aos programas de auditório, ao mesmo tempo um tanto afastada e silenciada pelos esquemas de censura do regime militar. Devido às limitações deste artigo, não é possível aprofundar tal contiguidade de mundos, ficando para outra oportunidade esse exercício. Porém, de forma sucinta, matérias na Revista Amiga apontam o sucesso que os "transformistas" brasileiros vinham fazendo no exterior e suas insurgências na cena pública por meio dos programas de auditório. Reportagens como "Valéria, um homem, uma mulher" (Amiga, 1972, n. 101, p. 8-9) chamam a atencão para as transformistas de fama internacional. Chacrinha, certa vez, comentou o sucesso de "nossa" Rogéria no exterior, da mesma forma que lamentava os constrangimentos sofridos pelas emissoras que decidissem levá-la ao ar. (Amiga, 1972, n. 133, p. 55).

6 Documentário "Rita Cadillac: a lady do povo" de Toni Venturi, 2010. 
masculino, criar com ele uma relação de confiança, trazendo-o sempre naquele mesmo horário para frente da TV. Por isso a ênfase dada por cada uma delas em formular uma maneira própria de olhar para a câmera. Até hoje as chacretes falam de aprenderem um olhar diferenciado para tentar "hipnotizar" o telespectador, ao mesmo tempo em que esse ato possuiria uma contrapartida negativa, a instauração de possíveis conflitos com as "donas-de-casa". Mas a disputa poderia fazer a telespectadora ficar mais ainda ligada na TV, para controlar o "hipnotizado" amante. Assim, nos termos das dançarinas, o conflito conjugal propiciado pelo domínio de uma determinada técnica corporal reverbera em audiência e não afasta do sofá o "público-alvo" do programa, as "donas-de-casa".

Logo, eram gestos mínimos que compunham a chacrete, porém eficientes, numa feminilidade que se despontava até mesmo entre os dedos, nos giros sensuais que faziam com eles e na maneira de deixar as próprias mãos eroticamente mais soltas, mas nunca relaxadas. O sorriso deveria estar sempre estampado em seus rostos, era uma exigência de Chacrinha. O telespectador chega cansado do trabalho, não pode olhar para mulheres sérias, costumava dizer. Cabia às chacretes oferecer-lhes alegria. Sorriso expressivo, alegre, aberto. Por isso era preciso sorrir durante todo o tempo, mesmo que fosse cansativo demonstrar tanta felicidade assim. As de pouco sorriso eram reprimidas. Edilma Campos se lembra das "broncas" de Chacrinha por pouco sorrir. "Você têm um sorriso bonito. Procure estar sempre com um sorriso nos lábios para as pessoas verem que aqui é um lugar de alegria, de festa, de encantamento. Procure sempre sorrir nas suas apresentações porque eu reparei que você não sorri". A persistência na "tristeza" poderia afastá-las do auditório e, devido a isso, Edilma pôs-se a sorrir. No entanto, não podia jogar beijos para as câmeras, atitude de "mulher que não presta". A ultrapassagem do limite do sorriso largo era o beijinho. Sorrir, sim. Mandar beijos, nunca.

Quanto à postura corporal, deviam as dançarinas ficar sempre eretas, ombros erguidos, queixo elevado acompanhado de um olhar altivo. As chacretes precisavam "manter a compostura", sobrevalorizando a bunda, elevando-a ao topo sempre que possível. Para isso, não podiam manter as mãos na cintura. A bunda devia ser destacada sem o auxílio das mãos. Era comum virarem o bumbum para as câmeras, ou pelo menos insinuá-lo. Não podia haver "corpo mole", barriga sobressalente, aparecer de pernas abertas. Era preciso controlar o corpo mesmo nos momentos de descanso, adotando poses altivas. A sensualidade devia estar presente mesmo quando paradas. $O$ pior de uma chacrete era ela apresentar-se prostrada, arcada, barriguda e de bunda "pra dentro" sem, portanto, o menor sex appeal. 
Ao longo da trajetória no programa, as dançarinas precisavam elaborar um estilo pessoal de se exibir, uma construção eficaz de si mesmas. Singularizar-se, não ser mais uma no palco, era o que injetava fervor nas performances das girls. A chacrete que se esforçava, fugindo do "feijão-com-arroz" da coreografia a ponto de criar um estilo próprio, era reconhecida entre os pares e valorizada no mercado erótico mais amplo no qual estavam inseridas (saíam mais em revistas, recebiam convites para fotos etc.). As dançarinas mais criativas, e consequentemente as mais famosas, conseguiram acoplar à homogênea coreografia suas próprias marcas, sempre com forte ênfase nas conotações sexuais. Mesmo que aparentassem, a princípio, semelhanças entre si, as grandes chacretes souberam aproveitar os momentos de destaque para brilhar, inovando e chamando a atenção num curto espaço de tempo, em seu momento-vírgula, através de uma hiperfeminilização de seus próprios atos no palco, já rotineiramente sensualizados durante suas aparições no decorrer do programa. A atração dedicava tão pouco tempo a elas, além de ser um grupo de cerca de 20 mulheres, que era preciso encontrar formas para se destacar durante as exibições.

A maior chacrete dos anos 1970, Índia Potira, é considerada a inventora da coreografia do "roda-roda" (há intrigas que buscam negar o fato, como em qualquer meio artístico competitivo). Antes de entrar os anunciantes, era costume soltarem um pequeno jingle agitado de autopromoção do programa que dizia: "Roda, roda, roda e avisa! Um minuto de comercial. Alô, alô Terezinha! É um barato a Discoteca do Chacrinha!”. As chacretes eram focadas pelos câmeras ao longo dessa pequena finalização.

Índia criou para esse momento uma maliciosa intimidade com o telespectador. Durante o close, passou a traçar círculos no ar com a ponta do dedo, cuja circunferência imaginária iria de sua região genital aos seios. Ao movimentar os braços na altura da cintura com o dedo indicador da mão direita apontado para o telespectador, sorrindo para as câmeras e rebolando sensualmente, a dançarina parecia fazer um convite erótico a quem a assiste. $\mathrm{O}$ círculo era referência direta ao "roda-roda" incitado pela música, mas ao mesmo tempo destacava as partes de seu corpo tão desejadas. Segundo ela, sua criação "surgiu do nada".

Só de tocar a música, falava de rodar. Eu comecei a rodar o dedo. Tinha umas [chacretes] que ficavam girando no queijo, pareciam barata tonta, era horrível! Uma chegou a cair lá de cima. Eu comecei a girar só o dedo, pra câmera, só isso. Não ficava rodopiando o corpo todo e não ficava tonta.

O sucesso dessa criação fez do movimento algo obrigatório para todas as dançarinas ao longo dos anos. As chacretes são lembradas até hoje por essa coreografia simples, porém, marcante. Todavia, a posterior generalização desse passo fez com que procurassem imprimir uma marca própria sobre a formulação de Índia, que de tão repetida perdeu a autoria, na luta incessante entre elas para se singularizarem perante as amigas. Algumas estendiam mais os 
braços, faziam uso dos dois membros, reduziam o tamanho da circunferência desenhada no ar, giravam para o alto, rebolavam de maneiras diferenciadas, movimentavam a cabeça de forma inusitada, modificavam os olhares, entre outras variações sobre o "roda-roda" criado por Índia.

O interessante é perceber que a mais famosa girl dos anos 1980, considerada a substituta de Índia Potira, inovou precisamente no "roda-roda", fazendo a maior diferenciação já realizada por uma chacrete sobre esta coreografia banalizada. Rita Cadillac subverteu qualquer expectativa em relação ao movimento. Passou não mais a estender o braço para frente do tórax, mas aproximá-lo do rosto. O giro com o dedo fazia uma pequenina circunferência, de alguns centímetros de diâmetro, na altura de sua boca, bem diferente das circularidades que ligavam a genitália aos seios. Rita não sorria e nem rebolava. A falta de um sorriso aberto vai de encontro às recomendações de Chacrinha, mas a seriedade tornou-se um diferencial no excesso de mulheres mostrando os dentes. Rita encarava eroticamente o espectador, bem séria, apenas com uma mão na cintura, bunda empinada e pernas entrecruzadas, sem qualquer movimento, apenas do dedo. Isso chamava a atenção para o rosto, deslocando finalmente a câmera da bunda para outra parte nem sempre valorizada. Diz ela:

\footnotetext{
Eu tinha que fazer alguma coisa diferente. Então eu botei na cabeça que eu era a gostosa do programa. Que eu era a mais poderosa do programa! Eu construí um personagem assim. (...) Tinha a chamada de comercial, o roda-roda. Todas faziam diferente. Faziam grande. Eu falei: 'pô, se eu fizer grande vai continuar igual. Vamos lá num pequeninho, assim no dedinho, para ficar na imaginação’?
}

Outro movimento típico e que reverbera nas práticas de hiperfeminilização era o que ficou conhecido como "chacretada". Ele era executado principalmente pelas mais escondidas no palco e sobre um pedestal. Era um passo considerado vulgar, principalmente entre as girls da linha de frente, por não precisarem "apelar" tanto para conseguir seu momento-vírgula. Costuma-se dizer que toda iniciante durante um período tinha que fazer "chacretadas". Com a câmera as focalizando de baixo para cima no queijo, as jovens mais desconhecidas tinham que descer rebolando até a proximidade das lentes. O cameraman com gosto fazia uma imagem de suas bundas cravadas por um maiô justo, que quase chegavam a roçar no aparelho eletrônico diante da proximidade. Outra forma de se insinuar ao telespectador na "chacretada" era movimentar a pélvis de forma que sua vagina ganhasse destaque por meio de contrações abdominais até o chão, estimulando um vai-e-vem frenético do órgão sexual perante as câmeras. Esse movimento, portanto, era visto como invasivo e um tanto humilhante pelas dançarinas. Fazê-lo era uma forma de ritual de passagem, algo necessário para permanecer no programa e abandonado depois de certa estabilidade na carreira.

\section{Incitações eróticas}

7 Documentário "Rita Cadillac: a lady do povo" de Toni Venturi, 2010. 
Portanto, a qualquer momento, as dançarinas se requebravam no palco e fabricavam hiperfeminilidades quando focadas pelas câmeras. O close era seu único momento de individualização, quando se desprendiam da balbúrdia do auditório, sendo preciso valorizá-lo ao máximo já que esse era bastante fortuito. Nesse momento de plano fechado, as dançarinas saíam do contexto distanciado do mero elemento que compunha um espetáculo para estabelecer um vínculo de simpatia com a plateia e com isso permitir alguma relação de identificação e reconhecimento.

Existia uma explícita intenção do apresentador em construir um momento de destaque para cada uma das dançarinas da linha de frente, dando a elas uma oportunidade ímpar de ousarem. Afinal, Chacrinha sempre foi o maior incentivador da erotização de suas girls. Era ele quem conduzia, instigava, provocava e exibia suas práticas hipersensuais, assumindo o papel de agenciador de superfêmeas. A linguagem grotesca do programa colocava o único homem da cena como um "corruptor" de mulheres, algo próximo do imaginário estereotipado da prostituição feminina popular e sua emblemática figura do cafetão, do gigolô (Fonseca, 2004).

$\mathrm{O}$ apresentador anunciava o nome artístico da dançarina e requisitava que ela viesse ao centro do palco ora para uma rápida dança, ora para conversar. "Maestro, um sambinha para Jurema Pacotão!". Jurema se deslocava com graça, desprendendo-se das amigas e, sozinha, começava a sambar uma música de sucesso, tornando-se a atração principal durante meio minuto. A boa solista devia preencher o palco com seus movimentos para ser sempre convocada. "My Boy [sonoplasta], uma pantera para Gracinha Copacabana!”. Ao som da sensual trilha sonora do filme Pantera Cor-de-Rosa, a dançarina fazia uma performance menos agitada, de descidas rebolativas vagarosas, para que a câmera focalizasse sua bunda arcada. O maiô cavado permitia que se observassem suas virilhas, além de deixar boa parte das nádegas de fora. A performance era acompanhada de comentários de Chacrinha. "Alô! Mostra mais, mostra aê!" ou "Que beleza! Que formosura da natureza!”. A plateia encorajava as jovens, pedindo mais e mais. Aplausos e pedidos de bis serviam como termômetros de popularidade e da aptidão da solista.

Bastante comum nessa interação com o público era quando Chacrinha jogava avanço roupas íntimas das girls. "Quem vai querer a calcinha da Fátima Boa Viagem! Aê!”. Outro recurso incitador eram comentários pré-gravados de uma voz masculina e lançados pelo sonoplasta ao longo do solo de uma chacrete, algo típico de programas de auditório. "Isso? Ah! Essa aí tem muito amor para dar!" e "É muita farinha para o meu pirão!" eram frases recorrentes. Uma nítida divisão de cor de pele marcava tais solos: as mulatas eram mais convocadas a sambar. A câmera pouco focalizava suas faces durante a dança, concentrando-se nas pernas e bunda, por meio do travelling. As louras eram as rainhas da música da pantera. A lentidão da dança permitia focalizar seus rostos 
quando agachadas, geralmente sérios e insinuantes, sem deixar de lado suas bundas, é claro. Negras e morenas pouco eram convocadas para o solo.

Nas hierarquias do palco, as chacretes tinham seus corpos "partidos" por meio do enfoque das câmeras. Cada uma possuía algo mais valorizado a ser filmado. No final das contas, eram reconhecidas publicamente por regiões do corpo. A parte representava o todo. Uma o sorriso, outra o olhar. Determinada bunda era mais arredondada e merecia atenção especial. Certa coxa era de uma grossura ímpar e alvo do close. A bunda de Rita Cadillac era tida pelos produtores como sua grande referência, a sua marca. Leleco Barbosa costuma dizer que "aquilo [bumbum de Rita] parece um cadillac. O cadillac era o carro da moda na época. Aquele rabo de peixe que tinha o cadillac! Ela tinha um corpo muito bonito, tinha uma bunda muito bonita, acentuada, como tem até hoje ainda. A grande marca dela era a bunda dela"8. A singularização das dançarinas se fazia também por ênfases dadas a partes de seus corpos, que as representavam por inteiro.

Em menor proporção, certos quadros do programa garantiam também algum grau de individualização: sortear e abrir cartas dos telespectadores, acompanhar os calouros ao microfone, entregar prêmios, anunciar produtos, segurar certos objetos e expô-los à câmera, cantarolar musiquinhas e mesmo auxiliar na administração da balbúrdia do auditório. $\mathrm{O}$ mundo artístico televisivo, resultado das ações coordenadas e cooperativas de grupos específicos de pessoas (Becker, 1982), exigia das chacretes uma gama variada de serviços a serem prestados, uns mais importantes do que outros, porém essenciais ao resultado final desse trabalho coletivo que é o programa de auditório.

\section{Vestimentas}

As vestimentas das girls tornaram-se um capítulo a parte em suas performances de superfêmea, uma vez que eram milimetricamente calculadas a fim de qualificarem e maximizarem seus corpos. Nos anos 1970, a roupa mais comum consistia num curto vestido, cuja base se estendia até metade das coxas e sem mangas, com os braços de fora e colo em destaque. As colorações eram variadas, com estampas floridas ou de cores fortes e chamativas, excelentes para o vídeo em preto-e-branco, às vezes fazendo referências a bandeiras de países e de times de futebol. Para variar, existiam roupas de short curto e miniblusas, deixando as barrigas à mostra. Botas de cano longo eram imprescindíveis e se estendiam até os joelhos, brancas ou pretas, e facilitavam o bailado.

A censura federal marcava em cima das vestimentas, o que não impedia que as jovens se envolvessem num minucioso ritual de preparação com o intuito 
de erotizar suas imagens9. Elas subiam as saias de seus vestidos acima do permitido, deixando à mostra o short que compunha o visual. Era comum solicitarem aos confeccionadores roupas de manequim menor, deixando-as extremamente justas, ressaltando os contornos das nádegas e pernas. Aquelas consideradas com um menor bumbum, a fim de valorizá-lo, costumavam usar roupas mais cavadas, que alargavam os quadris. Mesmo as "sem bunda", adquiriam um bumbum por meio de algumas malícias. Por sua vez, a maquiagem procurava colocar em foco os olhos, principal instrumento de comunicação. Os adereços - colares, pulseiras, prendedores de cabelo, etc tornavam-se o elemento mais variável entre elas. Por meio deles, compunham sua persona cênica: a faixa na cabeça e os cabelos trançados de Índia Potira, os braceletes da Loira Sinistra, o colar com as iniciais do nome de Lucinha Apache, a pequena tiara de Angélica, etc.

Todavia, a grande sensação estética era o uso de perucas, preferencialmente as de marca Lady e louras, cujo propósito era introduzir uma sensual diferenciação diante das roupas compartilhadas por todas. Chacrinha costumava financiar as jovens para que semanalmente comprassem meiascalças transparentes, evitando o uso de peças velhas e desfiadas. Ela daria mais estabilidade e brilho às coxas. Edilma conta que era comum os fãs não acreditarem na possibilidade de existência daquelas grossas coxas. Circulavam histórias sobre o uso por parte das girls de meia-calças importadas, que inflavam suas pernas. Beliscões de homens a fim de comprovarem a veracidade do torneamento tornaram-se constantes.

\section{Conclusões}

Gostaria de concentrar-me em tal desconfiança dos fãs para com os contornos corporais das chacretes a fim de concluir este artigo. Isso porque justamente esse descrédito nos remete ao investimento no corpo voluptuoso das chacretes e o quanto as regras de cálculo para sua gestão são colocadas em xeque diante de uma maximização que beira o inacreditável. Os fãs desconfiam da existência daquelas mulheres e seus corpos maximizados. Scott (1995) faz uso de duas interessantes metáforas em torno da ideia de gênero - a do "vazio" e a do "transbordamento" - que nos permitem pensar sobre as performances das chacretes, aquilo que tenho convencionado chamar aqui de superfêmea. Diz a autora:

9 Simões (1986: 78 e 2000: 79) revela que a maioria dos problemas de Chacrinha com a censura federal era relacionada às brincadeiras que fazia com o auditório, às saias e maiôs das chacretes e de algumas "tomadas de detalhes anatômicos" feitas pelas câmeras dos corpos das jovens. Por sua vez, todas as lembranças das chacretes do momento político da época sempre estão conectadas à imagem do censor a restringir o tamanho de suas vestimentas de dançarina momentos antes de entrar no palco. As recomendações iam no sentido de que a bota deveria ser a mais longa possível e chegar à altura dos joelhos. A saia também bastante comprida, quase chegando às botas. Assim, pareciam estar de calça, exibindo bem pouco de suas coxas grossas. Os seios deveriam estar cobertos, decotes apenas os mais modestos. 


\begin{abstract}
"Nós só podemos escrever a história desse processo [de emergência do feminismo] se reconhecermos que 'homem' e 'mulher' são, ao mesmo tempo, categorias vazias e transbordantes. Vazias, porque não têm nenhum significado último, transcendente. Transbordantes, porque mesmo quando parecem estar fixadas, ainda contêm dentro delas definições alternativas, negadas ou suprimidas" (Scott, 1995: 93).
\end{abstract}

Assim, meias, perucas e outros recursos que incrementavam e transbordavam os corpos tornavam as chacretes mais femininas do que a mais heterossexual das mulheres - algo próximo do que diz Perlongher (2008: 100) ao refletir sobre a prostituição viril em São Paulo -, sendo quase caricatas em suas incitações à hiperfeminidade. Elas descobriam nessa gestão dos corpos maiores chances de se comercializarem e fazerem sucesso. O tipo superfêmea era muito apreciado e por isso uma autopromoção extremamente feminilizada tornou-se tão imprescindível que os intensos investimentos nesse quesito eram capazes de serem alvos das desconfianças até mesmo por parte dos próprios fãs.

Butler (2003: 197) utiliza-se da expressão "paródia" para se referir às performances que questionam a possibilidade de um gênero original - isso que Scott nomeou de "vazio" e "transbordamento" - revelando o esforço com que ele é construído por meio de práticas que parecem fantásticas e deslocadas, e que ao invés de denunciarem a "cópia”, põe em dúvida o suposto original. As chacretes parodiavam as próprias mulheres heterossexuais ao elevarem a um alto grau a feminilidade socialmente esperada, demonstrando as possibilidades subversivas da sexualidade e do gênero nos próprios termos do poder. Elas maximizavam performaticamente as expectativas do que fosse uma mulher heterossexual "comum", "original" e traziam das margens para o centro da indústria cultural suas feminilidades transbordadas, excessivas, que jogavam luz sobre nossa compreensão do que é o feminino.

Ao exagerarem as características socialmente atribuídas ao seu sexo anatômico, as chacretes não embaralhavam propriamente a coerência entre sexo-gênero-sexualidade como ocorre nos casos dos "abjetos" (travestis, transexuais etc.). Falamos aqui, portanto, mais em termos de "graus" de gênero do que propriamente de "estado", percebendo o quanto "ser mulher" pode ser constantemente resignificado em suas próprias bases por meio da excitação visual e práticas cotidianas de uma dançarina que baila na televisão e excita seus telespectadores. 


\section{Referências Bibliográficas}

BECKER, Howard. Art Worlds. Berkeley/Los Angeles, University of California Press, 1982.

BISPO, Raphael. Gênero e carreiras artísticas na emergente indústria cultural brasileira. Comunicação e Sociedade, v. 21, p. 79-94, 2012.

BUTLER, Judith. Cuerpos que importan: sobre los limites materiales y discursivos del 'sexo'. Paidós, Buenos Aires, 2002.

Problemas de gênero: feminismo e subversão da identidade.

Rio de Janeiro, Civilização Brasileira, 2003.

HARAWAY, Donna. Manifesto Ciborgue: ciência, tecnologia e feminismosocialista no final do século XX. In: HARAWAY, D. et all. (orgs.). Antropologia do ciborgue: as vertigens do pós-humano. Belo Horizonte, Autêntica, 2009.

MAUSS, Marcel. As técnicas do corpo. In: MAUSS, M. Sociologia e Antropologia. São Paulo, Cosac Naify, 2003.

PERLONGHER, Néstor. O negócio do michê: a prostituição viril em São Paulo. São Paulo, Fundação Perseu Abramo, 2008.

SCOTT, Joan Wallach. Gênero: uma categoria útil de análise histórica. Educação \& Realidade. Porto Alegre, vol. 20, nº 2, 1995, p. 71-99.

SIMÕES, Inimá. TV à Chateaubriand. In: SIMÕES, I. et all (orgs.), Um país no ar: história da TV brasileira em três canais. São Paulo, Brasiliense/Funarte, 1986.

. Nunca fui santa (episódios de censura e autocensura). In: BUCCI, E. (org.), A TV aos 50: criticando a TV brasileira em seu cinqüentenário. São Paulo, Perseu Abramo, 2000. 